\title{
PROTOTYPE OF NATIONAL DIGITAL ELEVATION MODEL IN INDONESIA
}

\author{
Danang B. Susetyo ${ }^{1}$, Yustisi A. Lumban-Gaol ${ }^{1}$, Ibnu Sofian ${ }^{1}$ \\ ${ }^{1}$ Geospatial Information Agency (BIG), Jl. Raya Jakarta-Bogor Km. 46, Cibinong, Indonesia - (danang.budi, yustisi.ardhitasari, \\ ibnu.sofian)@big.go.id
}

Commission IV, WG IV/3

KEY WORDS: DEM, prototype, Indonesia

\begin{abstract}
:
Although medium scale mapping has been done for the entire territory of Indonesia, there has never been a DEM unification to produce seamless national DEM. The main problem to generate national DEM is multi-data-sources. Each of them has their own specification, so unification of data becomes not easy to do. This research aims to generate global DEM database in Indonesia. Because its coverage covers only one country, it is called National DEM. This study will be focused on the northern part of Sumatra island, precisely in the boundaries between Aceh and North Sumatra province. The principle method in this study was to rebuild DEM data by considering the height difference between ground elevation from masspoints and surface elevation from DSM. By setting up a certain threshold value, the filtering process was then performed. The output was generated by gridding process. Validation in this research was done by two methods: visual inspection dan statistical analysis. From visual inspection, the National DEM data becomes smoother than the input data, the reality of the data is maintained, and still shows the landscape of the DSM input. From statistical analysis, compared with 142 GCPs, it is obtained that Root Mean Square Error is $2.237 \mathrm{~m}$, and vertical accuracy based on Indonesian Mapping Accuracy Standard is $3.679 \mathrm{~m}$. The result is good for medium scale base map and, based on the standards in Indonesia, the data can be used for 1: 25,000 scale mapping.
\end{abstract}

\section{INTRODUCTION}

\subsection{Background}

Digital Elevation Model (DEM) is one of basic geospatial information product which is indispensable for national development. DEM data can be used for urban planning, disaster mitigation, and resources management. Because of that, DEM data provision in national scale is an urgency, especially in high resolution and good accuracy.

Until now, Indonesia does not have national DEM data, even in medium scale. Although medium scale mapping (combination of scale 1:25,000 and 1:50,000) has been done for the entire territory of Indonesia (Figure 1), there has never been a DEM unification to produce seamless national DEM. The main problem to generate national DEM is multi-data-sources, because there are several data sources used, i.e. TerraSAR-X, IFSAR, and Radarsat. Each of them has their own specification, so unification of data becomes not easy to do.

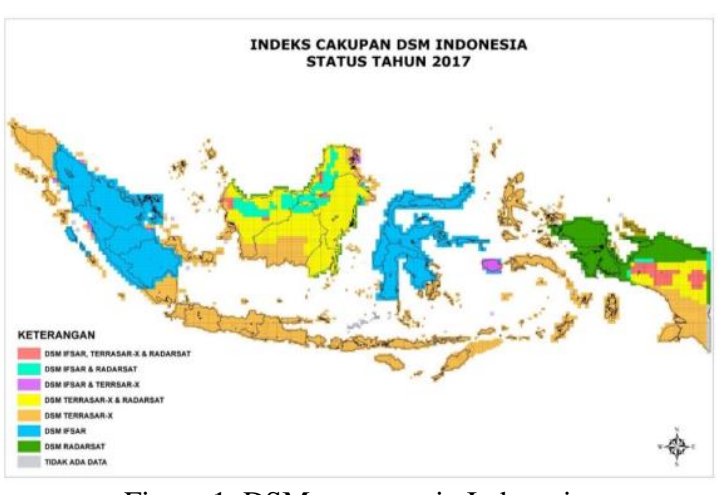

Figure 1. DSM coverage in Indonesia.
Global DEM development has been widely implemented in other countries. One of them is GLOBE (Global Land One-Km Base Elevation Digital Elevation Model). GLOBE was developed by an international group of specialists, cooperating with the Committee on Earth Observation Satellites (CEOS) Working Group on Information Systems and Services (WGISS), International Geosphere-Biosphere Programme's Data and Information System (IGBP-DIS), and IGBP Working Group IV/6 (Hastings \& Dunbar, 1998). The DEM's are generated from several topographic data sources, i.e. Digital Chart of the World (DCW) and Digital Terrain Elevation Data (DTED), where DTED is generalized from 3-arc-seconds to 30 arcseconds, adjusting to DCW which is a vector cartographic data set based on 1:1,000,000 Operational Navigation Charts (Gesch \& Larson, 1996). Another example of global DEM is Antarctic Peninsula DEM, which is derived from ASTER (Advanced Spaceborne Thermal Emission and Reflection Radiometer) Global DEM due to the needs of a complete DEM with, better than, $200 \mathrm{~m}$ pixel size and high positional and vertical accuracy (Cook, Murray, Luckman, Vaughan, \& Barrand, 2012). Another research about generating of a seamless DEM dataset is Yue et al. (2017) that applied adaptive outlier filter to blending SRTM (Shuttle Radar Topography Mission)-1, ASTER GDEM v2, and ICESat laser altimetry data. Data refinement to generate DEM in national scale was ever done by de Morisson Valeriano \& de Fátima Rossetti (2012) who unified SRTM data refinement from 3 " to 1" through kriging over the entire Brazilian territory. In Indonesia itself, although until now there is no national DEM data, Julzarika (2015) have done research about height model integration of ALOS PALSAR, ICESat/GLAS, X SAR, and SRTM C with has a vertical accuracy of 1.14 and $1.65 \mathrm{~m}$. 
This research aims to generate global DEM database as SRTM or ASTER GDEM in Indonesia. Because its coverage covers only one country, it is called National DEM. The National DEM should be better than global DEM already available, both in spatial resolution and vertical accuracy. This approach is similar with gridding heterogeneous bathymetric data sets for the compilation of Digital Bathymetric Models (DBMs), because it is also has specific problems from extreme variations in source data density (Hell \& Jakobsson, 2011).

One of the policies assisted by the National DEM data is the determination of the coastline. One method to determine coastline is by delineating based on Digital Terrain Model (DTM) data with a certain height reference (Oktaviani, Ananto, $\&$ Basyiroh, 2015). The delineation of the coastline will have an effect on the borderline, which can affect something more sensitive like the local budget in each region. The most obvious example is the village fund, where the area becomes one of the parameters in the calculation (Hidayat, Sutisna, \& Riadi, 2015). Therefore, it can be concluded that national DEM data will have great benefits in determining policy and development planning in Indonesia

\section{MATERIALS AND METHODS}

\subsection{Study site}

This study will be focused on the northern part of Sumatra island, precisely in the boundaries between Aceh and North Sumatra province. This area was chosen due to the complexity of the data source and its landscape. The topography is a combination of urban, hill, forest, and coast. The illustration of the area is shown in Figure 2.

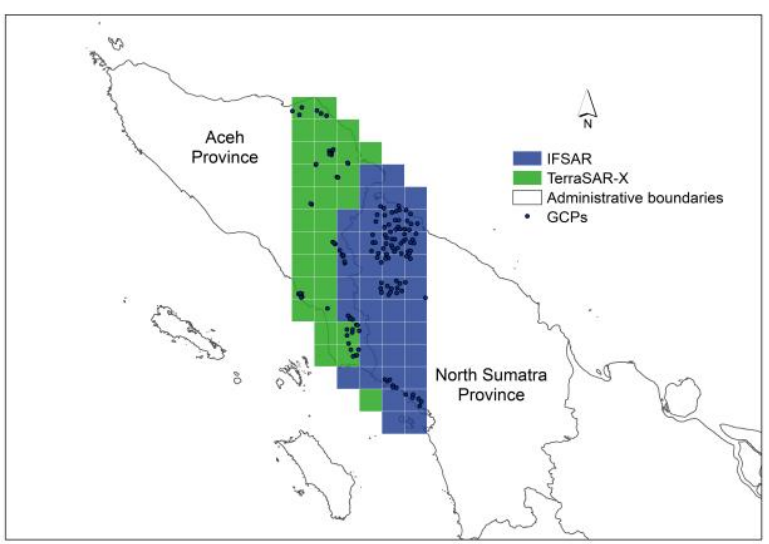

Figure 2. The area of study in the boundaries between Aceh and North Sumatra, with the distribution of GCPs.

\subsection{Data}

The study used some data sets which available in BIG, namely TerraSAR-X, IFSAR, masspoints, and Ground Control Points (GCPs). TerraSAR-X and IFSAR data represent the Digital Surface Model (DSM). DSMs from these data in the study area were consists of 69 scenes, precisely 39 scenes were from IFSAR and the rest were from TerraSAR-X. Second data sets were the masspoints which generated from stereo-plotting process. The density of the masspoints was about 20 to $50 \mathrm{~m}$ depends on the topographic contours. The craggy contours would have more mass-points than the flatter one. Last, GCPs data were used for validation. GCPs was measured using Global Positioning System (GPS) technology to acquire $\mathrm{dm}$ level of vertical accuracy, precisely below $3 \mathrm{dm}$. The study used 142 GCPs which distributed over the study area (Figure 2).

\subsection{Method}

Before the data processing began, all data sets should be ascertained already in the same reference system. The vertical reference system used in this study was EGM2008 and for horizontal (longitude and latitude) was WGS84. Also, the TerraSAR-X and IFSAR data need to be resampled to unify the resolutions by using cubicspline method. After that, the combining process was done to concatenate the DSMs.

The principle method in this study was to rebuild DEM data by considering the height difference between ground elevation from masspoints and surface elevation from DSM. By setting up a certain threshold value, the filtering process was then performed. The output was generated by gridding process.

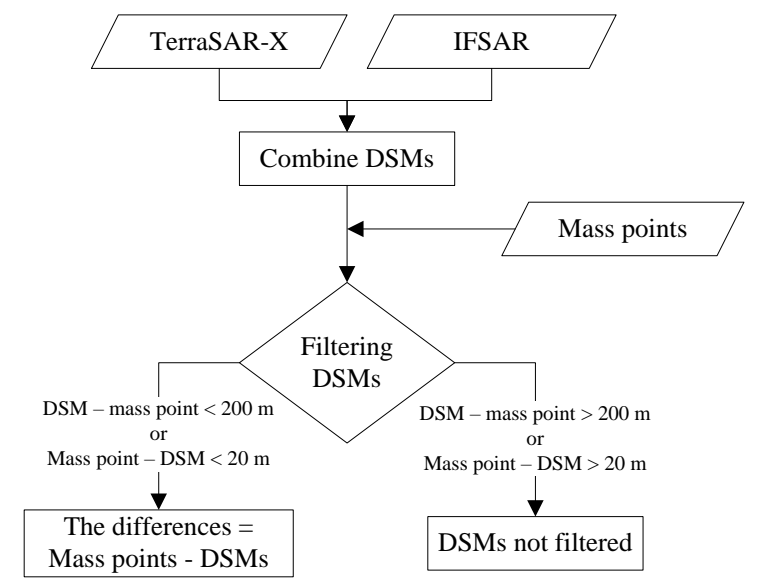

Figure 3. The algorithm of the DSM filtering based on a threshold value of differences between DSM and masspoints.

As shown in Figure 3, the filtering stage used some conditionals in the difference between the DSMs and the masspoints. If the DSM minus the masspoint was less than $200 \mathrm{~m}$ or the masspoint minus the DSM was less than $20 \mathrm{~m}$, then the DSMs were filtered by calculating the differences. In other words, the elevation in the masspoints would substitute the elevation in the DSM. If otherwise, then the DSMs were not filtered. The threshold value of 200 and $20 \mathrm{~m}$ was determined considering the cliffs and an assumption of the acceptable of masspoints error. These filtering process would generate the surface which contained the information of height differences between the DSMs and the masspoints.

Furthermore, the operators error when they put the floating mark to generate masspoints in stereoplotting process was also considered. Weighting was applied based on the height differences as shown in Table 1 , and the program code used is shown in Figures 4 and 5. The weighting process was done to expect the DEM output can be more realistic.

\begin{tabular}{|c|c|}
\hline $\begin{array}{c}\text { Range of height differences } \\
(\mathrm{m})\end{array}$ & Weight \\
\hline$<=0$ and $>=-3$ & 0.75 \\
$<-3$ and $>=-10$ & 0.70 \\
$<-10$ & 0.70 \\
$>0$ & 0.40 \\
\hline
\end{tabular}

Table 1. Weighting based on height differences 


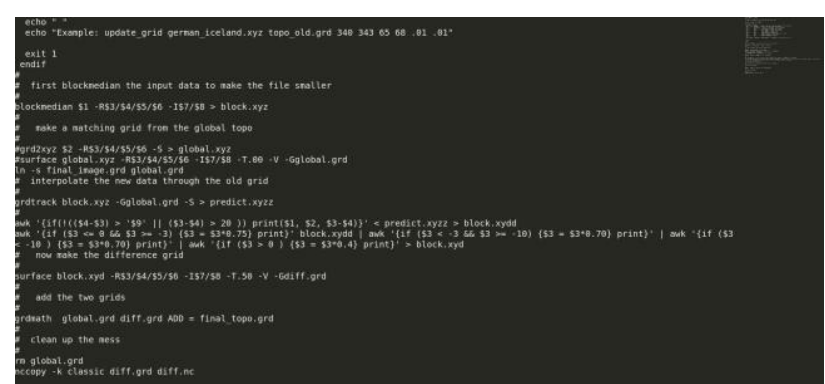

Figure 4. Code program (1)

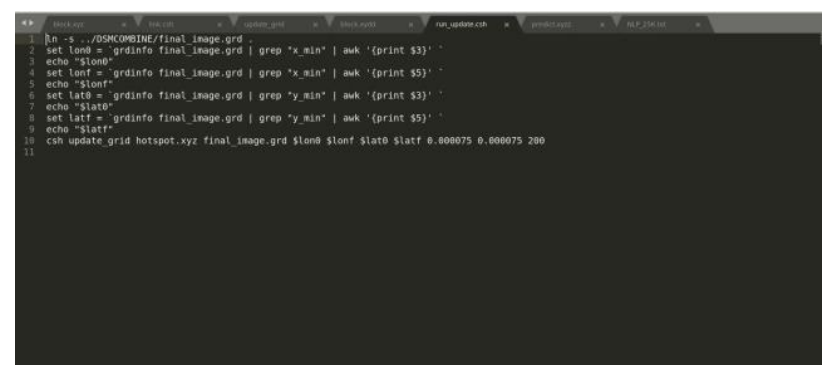

Figure 5. Code program (2)

The result from filtering and weighting were then added into the combined DSMs to generate the final topography or DEM. In order to evaluate the result, the validation was done by using 142 GCPs to compare with the resulted DEM. The residuals and root mean square (RMS) error were calculated to assess the quality. The RMS value was then reconciled to the standard of mapping accuracy as said in Indonesian Mapping Accuracy Standard.

\section{RESULTS AND DISCUSSION}

As described in the previous chapter, the principle method in this study was to rebuild DEM data by considering the height difference between ground elevation from masspoints and surface elevation from DSM, and by setting up a certain threshold value, the filtering process was then performed. The process is used to correct the terrain elevation from the resulting DTM to be accurate and realistic.

Figure 6 shows the differences between height value from masspoints and DSM. The difference is still considered to have errors, so it is necessary to make corrections. The correction parameters used are two: thresholds based on data reality and operators error, both of which have been described in the method chapter. The correction results based on the threshold parameters are presented in Figure 7, while the correction based on the operator error parameter is presented in Figure 8. The new height values are used to generate the new DTM.

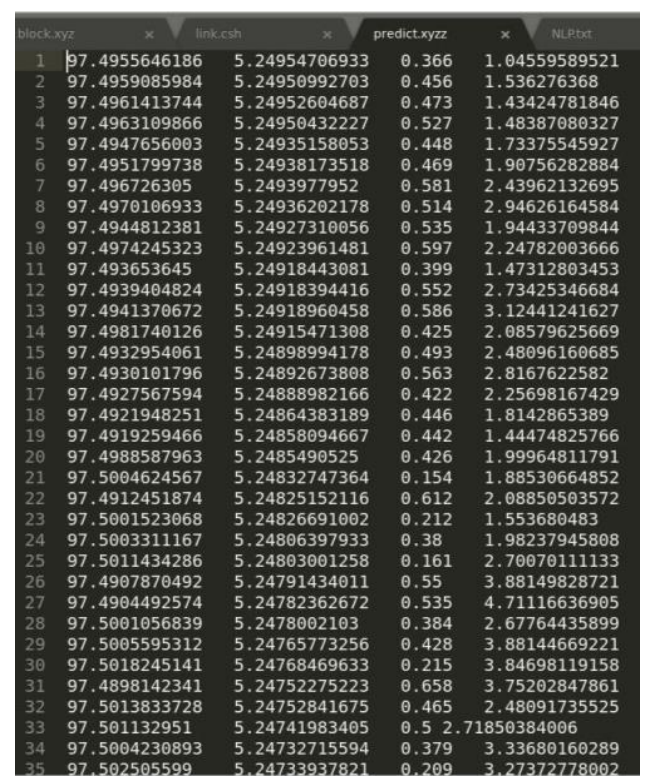

Figure 6. The differences between height value from masspoints and DSM (column: longitude, latitude, height, height difference).

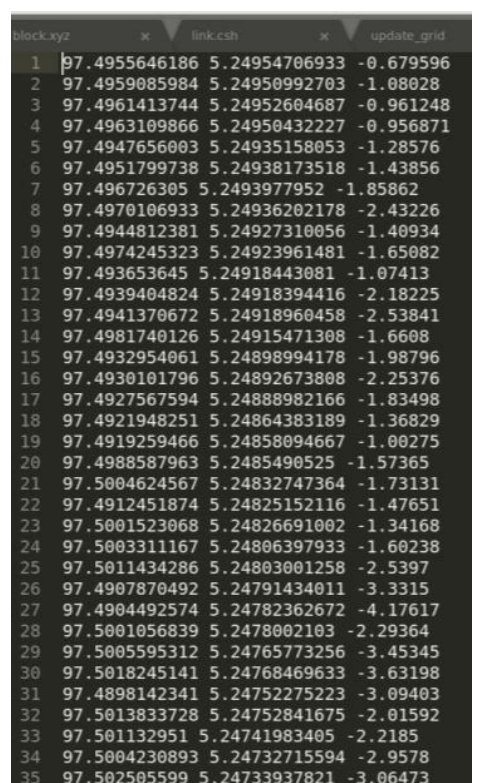

Figure 7. Height differences after corrected with threshold parameter (column 3). 


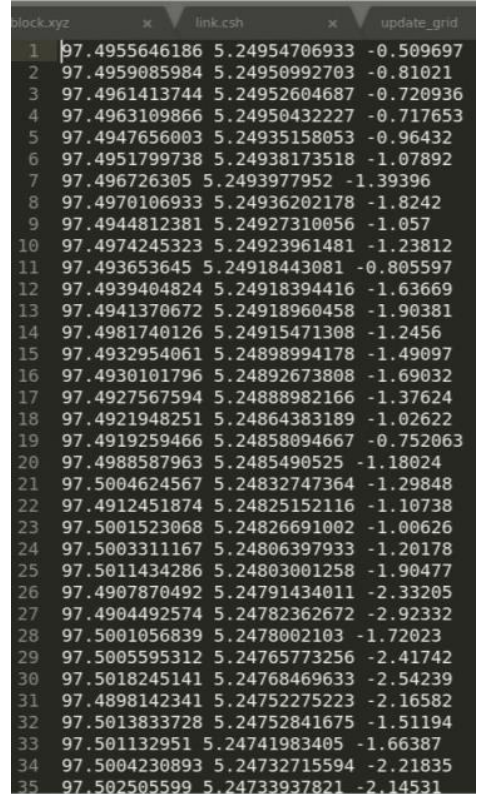

Figure 8. Height differences after corrected with operators error parameter.

Validation in this research was done by two methods: visual inspection dan statistical analysis. Visual inspection helps to identify structural irregularities in the data processing, deviations in comparison to other DEM datasets, systematic artifacts, and outliers inside the elevation model, and the statistical analysis is the most important step of the validation process (Kiefl, Koppe, \& Hennig, 2010). As mentioned in the introduction chapter, the purpose of this research is to produce a prototype of National DEM data for the whole of Indonesia. Therefore, various data sources with different specifications should produce a seamless DEM data output. Visual inspection is used to ensure the purpose of this research, so that the resulting data becomes smooth and seamless.

The figures below show the results of data processing in the border of TerraSAR-X and IFSAR. It can be seen in Figure 9 that visually TerraSAR-X and IFSAR DSM have very different level of detail. Actually, the problem of data difference is not only about the visual, but also the possibility of gap between scenes and data quality differences. In fact, global DEM should be free from both problems, so the resulting data to be smooth even though produced from different data.

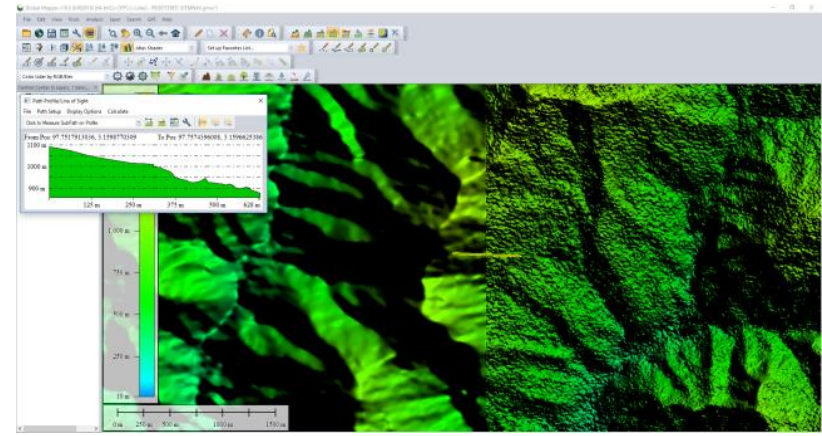

Figure 9. Visualization of TerraSAR-X (left) and IFSAR (right) DSM.

Results of data processing shown in Figure 10. It can be seen that the National DEM data becomes smoother than the input data. Nevertheless, topographically the National DEM data has not changed significantly, so the reality of the data is maintained.

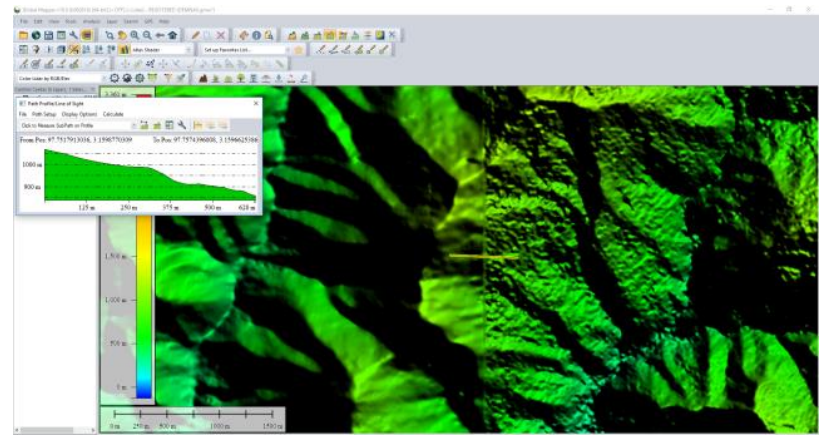

Figure 10. Visualization of DEM National in the same location with Figure 2

Visual inspection is also used to ensure that the realities of National DEM data are maintained. This process produces DTM by calculating the difference between surface and terrain. Although the DEM generated in this research is a visualization of ground, the filtering process should not change the landscape of the DSM input, including not too flat so that the DEM data becomes less realistic. The figure below shows the DTM comparison of this research process (Figure 11) and DTM generated only from masspoints (Figure 12). It can be seen that the DTM generated only from masspoints seems a little unrealistic because it is too flat, while the DTM generated from this research still shows the landscape of the DSM input.

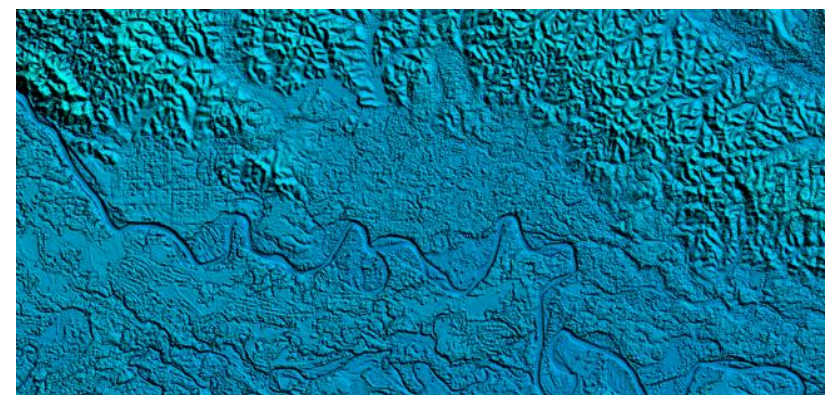

Figure 11. DTM from this research (National DEM)

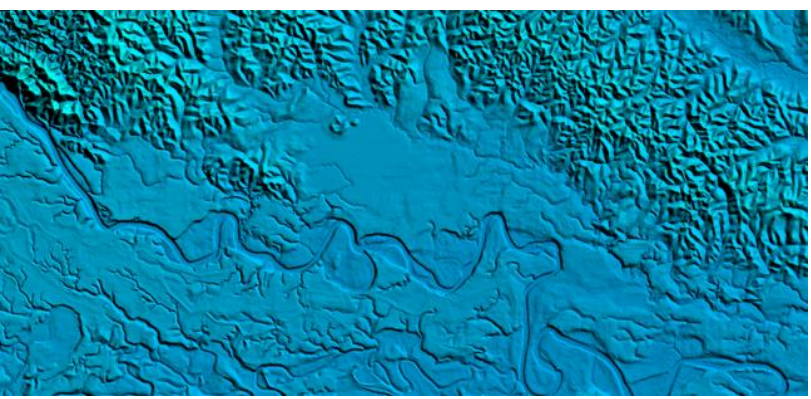

Figure 12. DTM only from masspoint

The second validation method is statistical analysis. Statistical analysis was done by testing the vertical accuracy of the resulting DEM data. Unavoidably, some errors will be present in each of the three dimensions of the spatial $(\mathrm{X}, \mathrm{Y}, \mathrm{Z})$ coordinates of the points occurring on DTM surfaces (Li, Zhu, \& Gold, 2005). Validation of DEM data accuracy can be done by referring the comparison with a more accurate DEM (Sefercik, Schunert, Soergel, \& Watanabe, 2012) or using Ground Control Points (GCPs) (Mukherjee et al., 2013), but in this research reference 
data used only GCPs. The results of the accuracy then compared Indonesian Mapping Accuracy Standard which is currently a reference to the accuracy of the base map in Indonesia.

On the standard, the statistical calculations are based on a $90 \%$ linear error (LE90) for the vertical accuracy. It specifies that $90 \%$ of the well-defined points that are tested must fall within a specified tolerance (Widyaningrum, Lindenbergh, Gorte, \& Zhou, 2018). LE90 is obtained by multiplying factor 1.6499 to Root Mean Square Error (RMSE), so that vertical accuracy of base map is:

LE90 $=1.6499 \times$ RMSEZ

with

$\mathrm{RMSE}_{\mathrm{Z}}=\sqrt{\sum\left(z_{\text {data }}-z_{\text {check }}\right)^{2} / n}$

where $\mathrm{n}$ is total number of check points on the map.

We compare elevation in National DEM and GPS measurements using 142 Ground Control Points (GCPs). The result, it is obtained that Root Mean Square Error is $2.237 \mathrm{~m}$, and vertical accuracy based on Indonesian Mapping Accuracy Standard is $3.679 \mathrm{~m}$. The result is good for medium scale base map and, based on the standards used in Indonesia, the data can be used for 1: 25,000 scale mapping.

\section{ACKNOWLEDGEMENTS}

The authors acknowledge Indonesian Geospatial Information Agency (BIG), especially Center for Topographic Mapping and Toponym for providing the datasets that used in this research.

\section{REFERENCES}

Badan Standardisasi Nasional. (2015). SNI Ketelitian Peta Dasar. Jakarta.

Cook, A. J., Murray, T., Luckman, A., Vaughan, D. G., \& Barrand, N. E. (2012). A New 100-m Digital Elevation Model of the Antarctic Peninsula Derived from ASTER Global DEM: Methods and Accuracy Assessment. Earth System Science Data. https://doi.org/10.5194/essd-4-129-2012

de Morisson Valeriano, M., \& de Fátima Rossetti, D. (2012). Topodata: Brazilian full Coverage Refinement of SRTM Data. Applied Geography, 32(2), 300-309. https://doi.org/10.1016/j.apgeog.2011.05.004

Gesch, D. B., \& Larson, K. S. (1996). Techniques for Development of Global 1- Kilometer Global 1-Kilometer Digital Elevation Models, (January 1996).

Hastings, D. A., \& Dunbar, P. K. (1998). Development and Assessment of the Global Land One-km Base Elevation Digital Elevation Model (GLOBE). ISPRS Commission IV - GIS Between Visions and Applications, 32 (4), 218-221. Retrieved from http://www.isprs.org/proceedings/XXXII/part4/hastings54.pdf

Hell, B., \& Jakobsson, M. (2011). Gridding Heterogeneous Bathymetric Data Sets with Stacked Continuous Curvature Splines in Tension. Marine Geophysical Research, 32(4), 493501. https://doi.org/10.1007/s11001-011-9141-1

Hidayat, F., Sutisna, S., \& Riadi, B. (2015). Permasalahan Data
Geospasial untuk Perhitungan Alokasi Dana Desa dalam Kerangka PP Nomor 60 Tahun 2014. In Seminar Nasional Peran Geografi Dalam Mendukung Kedaulatan Pangan. Cibinong.

Julzarika, A. (2015). Height Model Integration Using ALOS PALSAR, X SAR, SRTM C, and IceSAT/GLAS. International Journal of Remote Sensing and Earth Sciences, 12(2), 107116.

Kiefl, N., Koppe, W., \& Hennig, S. D. (2010). Terrasar-X Stereo Digital Elevation Models for Complex Terrain Conditions in Alpine Regions and Its Suitability for Orthorectification Purposes of Optical and Sar Imagery. In ISPRS TC VII Symposium (Vol. XXXVIII, pp. 333-336). Vienna, Austria.

Li, Z., Zhu, Q., \& Gold, C. (2005). Principles and Methodology. Boca Raton, London, New York, Washington D.C.: CRC Press.

Mukherjee, S., Joshi, P. K., Mukherjee, S., Ghosh, A., Garg, R. D., \& Mukhopadhyay, A. (2013). Evaluation of Vertical Accuracy of Open Source Digital Elevation Model ( DEM ). International Journal of Applied Earth Observations and Geoinformation, 21, 205-217. https://doi.org/10.1016/j.jag.2012.09.004

Oktaviani, N., Ananto, J., \& Basyiroh, N. N. (2015). Pemodelan Garis Pantai Kota Semarang Menggunakan Data Shuttle Radar Topography Mission (SRTM) dan Peta Lingkungan Pantai Indonesia (LPI). In PIT XII ISOI.

Sefercik, U. G., Schunert, A., Soergel, U., \& Watanabe, K. (2012). Validation of DEMs Derived from High Resolution SAR Data: A Case Study on Barcelona. In ISPRS Annals of The Photogrammetry, Remote Sensing and Spatial Information Sciences (Vol. I-7, pp. 49-54). Melbourne, Australia: XXII ISPRS Congress, 25 August - 01 September 2012.

Widyaningrum, E., Lindenbergh, R. C., Gorte, B. G. H., \& Zhou, K. (2018). Extraction of Building Roof Edges from LiDAR Data to Optimize the Digital Surface Model for True Orthophoto Generation. In ISPRS TC II Mid-term Symposium "Towards Photogrammetry 2020” (Vol. XLII). Riva del Garda.

Yue, L., Shen, H., Zhang, L., Zheng, X., Zhang, F., \& Yuan, Q. (2017). High-quality Seamless DEM Generation Blending SRTM-1, ASTER GDEM v2 and ICESat / GLAS Observations. ISPRS Journal of Photogrammetry and Remote Sensing, 123, 20-34. https://doi.org/10.1016/j.isprsjprs.2016.11.002 